\title{
11 Rules of Design for Manufacturing when Producing Pre- Impregnated Carbon Fiber-Reinforced Plastic Components - an Application at SAAB Aerostructures
}

Sara Nilsson, Jonas Jensen, Mats Björkman, and Erik Sundin

Linköping Univ.

CITATION: Nilsson, S., Jensen, J., Björkman, M., and Sundin, E., "11 Rules of Design for Manufacturing when Producing PreImpregnated Carbon Fiber-Reinforced Plastic Components - an Application at SAAB Aerostructures," SAE Technical Paper 2016-012124, 2016, doi:10.4271/2016-01-2124.

Copyright (C) 2016 SAE International

\begin{abstract}
Carbon fiber-reinforced plastic (CFRP) is one of the most commonly used materials in the aerospace industry today. CFRP in preimpregnated form is an anisotropic material whose properties can be controlled to a high level by the designer. Sometimes, these properties make the material hard to predict with regards to how the geometry affects manufacturing aspects. This paper describes eleven design rules originating from different guidelines that describe geometrical design choices and deals with manufacturability problems that are connected to them, why they are connected and how they can be minimized or avoided. Examples of design choices dealt with in the rules include double curvature shapes, assembly of uncured CFRP components and access for non-destructive testing (NDT). To verify the technical content and ensure practicability, the rules were developed by, inter alia, studying literature and performing case studies at SAAB Aerostructures. The research was done through a collaboration between Linköping University and SAAB Aerostructures in a state-funded project. This ensured a balanced approach between academic advancement and usefulness in commercial projects.
\end{abstract}

\section{Introduction}

The development and manufacturing of modern commercial aircraft are large and expensive commitments. This is especially true in the larger categories, where Boeing and Airbus together have effectively created a monopoly. At the same time, the demand for commercial aircraft has increased steadily during the 2010 s, and is expected to continue to do so during the next 20 years [1] .

Manufacturers have changed the way they operate. They have decreased their in-house manufacturing, and instead created a tiered system of suppliers that develop and manufacture the parts or systems that are then assembled by for example Boeing or Airbus [2]. One of these suppliers, SAAB Aerostructures in Linköping, develops and manufactures several parts for both companies, for example the ailerons for the Airbus A320 family and the cargo doors for the Boeing 787 family []] .
Performance demands for the commercial aircraft of the future have also changed. A bigger focus has been put on lowering operating costs and reducing environmental effects. Both of these demands have a strong correlation to fuel consumption, which in turn is connected to the effectiveness of the engines and the weight of the aircraft. The latter is the primary concern for a supplier like SAAB, and to meet these demands, parts and systems are developed with more complex geometries and more advanced materials.

The demand for reduction of weight has increased the use of CFRP in the aerospace industry. The material has a strength-to-weight ratio that is several times higher than aluminum and steel (however CFRP is sensitive to manufacturing defects that can be barely visual and might reduce the strength in the material). This makes it suitable for many applications where a low weight is crucial while maintaining strength and stiffness. It is specifically CFRP in pre-impregnated form that has made its way into the aircraft. Pre-impregnated CFRP is an anisotropic material that lets the designer control its properties to a high level of detail, but it also limits the design space compared to conventional materials and manufacturing processes.

As the material and its manufacturing methods are still developing, it can be difficult to determine how they affect a product's design and performance. Although a wealth of knowledge exists about the material itself and the manufacturing processes in both academia and industry, there is still a need for aggregation, where this information is structured and presented in a useful way. E.g. US Department of Defens [4] has an extensive handbook with almost 700 pages of relevant information. Several more examples exist of information heavy sources that the designer cannot take in and use and apply in day-to-day work.

\section{Aim and Delimitations}

Motivated by the lack of aggregated knowledge on how manufacturing and material affect the design of a component, the aim of this paper was to develop easy to understand design guidelines and rules for pre-impregnated CFRP structures. By describing how 
specific design choices affect the manufacturability of parts, the goal of the design guidelines and rules is that they should lead to CFRP products that are easier to produce. This in turn should reduce costs, raise the quality of the products and shorten lead times by e.g. facilitating the introduction of new materials or minimizing the risk of late changes. This aim delimits other aspects e.g. maintenance that of course also needs to be taken into consideration when designing components but is not the focus of this paper. Another delimitation is that this paper only considers the specific CFRP material that is used at SAAB Aerostructures, more about this can be read in the section; Material properties.

\section{Methodology}

The design guidelines and rules were created as a part of a bigger Design for Manufacturing and Assembly (DFM/A) project at SAAB Aerostructures, where the entire design process of CFRP components was examined. As a part of this work, different Masters of Science and a Bachelors of Science theses projects were carried out. These theses addressed different aspects of the main research task. Some previous results have been published by Andersson et al. []ㅡ and Jensen and Nilsson [] $]$.

Most knowledge in this study was gathered from empirical studies of the CFRP manufacturing process at SAAB Aerostructures, and data was collected through interviews [구 $\underline{8}]$, workshops [9] $]$ and observations $[\underline{7}, \underline{8}]$. The findings were sorted by cluster analysis $[\underline{10}]$ and served as the foundation for the eleven guidelines. Supporting theory about the materials' properties was used to understand what actually caused the issues. By supporting empirical findings with existing knowledge, the guidelines could be verified against theory [ㅁ]

A short summary of each guideline was created and referred to as rules (the list can be found under the section; Summation of the rules). The rules' purpose was to ensure that the guidelines were considered in the design process and the guidelines' purpose is to understand the rules. When the rules are not possible to apply, the designer would at least be able to anticipate potential manufacturing problems. In that way, the potential problem can be prevented in other ways than by adapting the geometry e.g. extra controls during the manufacturing or extra careful manufacturing instruction in order to secure quality in the component.

By applying the rules to five products manufactured by SAAB Aerostructures and comparing the result with actual manufacturing issues in the production, practical verification of the guidelines and rules was possible [9]. The results from the verification showed that manufacturing problems that exist with the products today was identified when applying the rules. The products used in the verification had different level of maturity in the company, and therefore gave a good prediction of different manufacturing issues.

\section{Carbon Fiber-Reinforced Plastic}

In this section, relevant material properties that are considered in the rules and guidelines are presented, followed by a description of the manufacturing process upon which this study is based.

\section{Material Properties}

Carbon fiber-reinforced plastics come in several different forms, but the common properties are that it consist of a polymer matrix and reinforcing carbon fibers [11]. In this study, the primarily studied material is the one used at SAAB Aerostructures, namely preimpregnated laminates with unidirectional PAN fibers and an epoxy matrix. Since both the matrix and fiber play an important role in the materials property, everything is not possible to transfer directly to other types of CFRP materials, which needs to be kept in mind even though the following descriptions are held at a rather general level.

At SAAB Aerostructures, and in most of the aerospace industry, the CFRP comes as pre-impregnated laminates with an epoxy matrix and unidirectional carbon fibers. Pre-impregnated CFRP means that the fibers have already been mixed with the matrix during fabrication, and that no additional substances are needed to manufacture the finished parts [12].

Since epoxy hardens at room temperature, the material has to be stored at low temperatures before manufacturing [13]. This means that the material has to be transported and stored in freezers, and when it is time for manufacturing, the process has to be fairly quick to prevent it from hardening at the wrong time. This also means that the laminates are sticky during manufacturing, which obstructs assembly and creates problems with dirt and pockets of air in the material [13].

The optimal result when manufacturing CFRP is to create a material with an even distribution of fibers and matrix throughout the material, where the two elements combine to form strong and rigid parts [13] In reality, the differences in distribution make it hard to predict how the hardening process will affect the final part. Internal stresses are created when the matrix is hardened and shaped [11]. These stresses can force the material to delaminate, or create a spring-back effect which affects the finished parts' structural integrity and shape, respectively [14]. Irregularity is normally prevented by laying the laminates cross-piled and symmetrically over a mid-plane [11]. Designers can also use the direction of the fibers, in a similar way, to manipulate the material's properties and behavior [11].

Differences in distribution of the matrix and fibers also lead to deviations in the thickness of the finished parts [13]. During the hardening of CFRP the thickness will be affected by local accumulations of the matrix, and it can be very hard to create parts where the thickness, and smoothness, are controlled.

Fiber direction is an important factor when draping complex shapes e.g. double-bent surfaces. Unidirectional laminates does not have the same possibilities as woven laminates for draping and the risk for deformation of the fibers is high [11].

When CFRP is hardened the matrix, in this case epoxy, acts as a glue to bind the fibers. This also glues the material to the mold used to shape the part, which requires the use of release agents [13]. In addition, this limits the design space of CFRP components because of the need for positive release angles for the material [15]. 


\section{Manufacturing Process}

The manufacturing process study carried out during the research for this paper, and the one described in this chapter, is specific for SAAB Aerostructures but typical for the aerospace industry. The process primarily involves CFRP in pre-impregnated laminates with unidirectional fibers for an optimal strength-to-weight ratio, and can be performed both manually and automatically.

To better describe the process, this paper has divided it into two parts: the first explaining the process taking the material from the freezer to a hardened part, and the second discussing finishing the part for assembly. The first part of the process, seen below in Figure 1, is described in the following text.

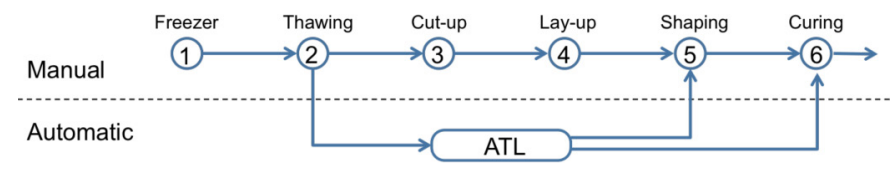

Figure 1. Illustration of the initial steps of the manufacturing process.

1. Before the manufacturing process is started, the pre-impregnated material is stored in freezers to keep the matrix from hardening.

2. When the material is needed for manufacturing, it first needs to be thawed so that it becomes less rigid and easier to work with.

3. The laminates are then cut into shapes corresponding to the shape of the desired part.

4. The cut-up laminates are then layered on top of each other with the fibers in different directions to achieve the optimal strength.

5. To get the correct geometry, the laminates are laid-up on a shaping mold. The components can either be shaped by hand or with the help of a vacuum. If the component has a simple geometry the lay-up can be done at room temperature; and with more complex geometry shaping, can be facilitated by performing it in a heated environment.

6. After the component is shaped it is cured in an autoclave. The cured component is then demolded from the mold.

This process can also be done partially automatically with Automatic Tape Laying (ATL). The ATL machine can cut the laminate shapes, arrange the laminates and, with easier shapes, shape the part on a shaping mold.

Before the component can be used in assembly it has to go through finishing work (e.g. trimming) and NDT. This second part of the manufacturing process, seen below in Figure 2, is described in the following text.

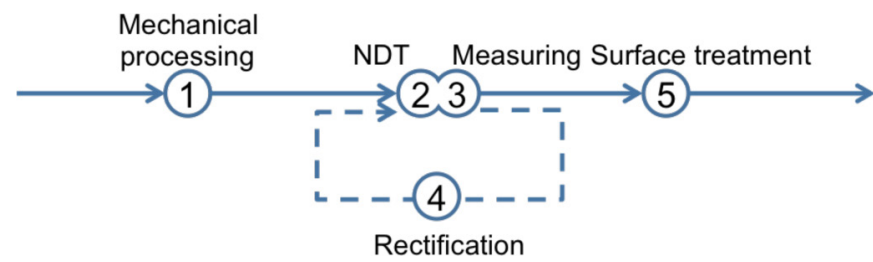

Figure 2. Illustration of the second part of the manufacturing process.

1. After the CFRP part is demolded it goes through a machining process to e.g. remove sharp edges, drill holes and be cut into the correct shape.
2. To ensure the strength of the structure of the component, it then has to go through NDT. This is typically performed with ultrasound, and the primary objective is to check if dirt or air has gathered in-between the laminates [13] .

3. In combination with the NDT, the component also needs to be measured to secure that the part has the correct dimensions within allowable tolerances. This is typically done with the help of lasers and cameras.

4. If some anomalies are detected during Steps 2 and 3, the component will either be scrapped or sent off line for corrections. This can mean several things, e.g. adding laminates of CFRP or adding epoxy. After the corrections are made the component will once again be sent through NDT and measuring.

5. The last step involves surface treatment, which typically means painting the component with epoxy-based paint.

\section{Development Process}

Applying a structured development process with useful tools provides an easier process for structured and well-supported decisions [10]. The early stages of the development process have a high impact on the final performance of the developed concept $[\underline{16}, \underline{17}, \underline{18}]$. Time spent on understanding how different design choices influence the manufacturing process will be recovered later in the development process [18]. Misunderstandings between different departments can also be highly influential on how well the development process is carried out. This is often due to the so-called "over the wall" problematic, where results from different departments are handed on without getting input on how the result influences the upcoming steps [16]. These problems can partly be solved with structured work processes where cross-functional teams have to cooperate and help each other [19].

\section{DFM Guidelines and Rules}

The guidelines developed for this project, together with a description of the underlying problematic and illustrative pictures, are presented in this chapter. Each guideline is concluded with a summative design rule; these are later aggregated in the section Summation of rules.

\section{Double-Bent Surfaces}

The biggest problem with double-bent surfaces comes from the difficulties in draping CFRP laminates. CFRP in the shape of pre-impregnated laminates can only be bent in one direction at a time [20]. This results in gaps and overlaps that in its turn lead to compromised strength in the material [11]. An example of this can be seen in Figure 3.

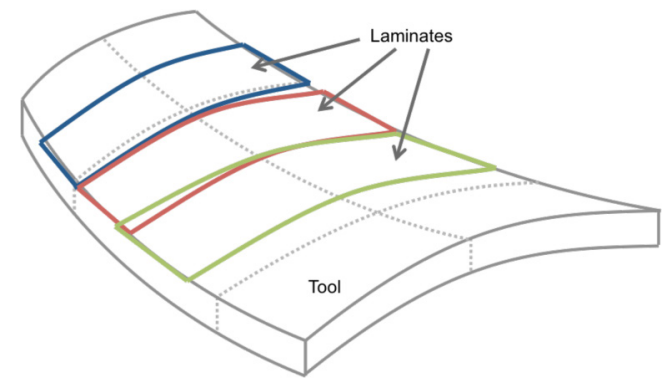

Figure 3. Example of how double-bent surfaces of pre-impregnated material create gaps and overlaps 
Another problem with double-bent surfaces is their dependency on the materials property that makes every material differently suitable to drape [14]. This means that the material needs to be considered when a design is evaluated. The level of double-bending also needs to be considered, i.e. that one or both radii are big enough to ease the negative aspects or make them irrelevant.

Double-bent surfaces can also contribute to problems of creating a symmetrical fiber direction through the material [14]. This can lead to distortions in the component when cured. Due to the same principles, problems can also occur with a stronger spring back effect in the component when cured [14].

Rule 1. Avoid double-bent surfaces as much as possible.

\section{Z-Shaped Cross-Sections}

If the laminates have to be shaped in a Z-profile, the cross-section has to be shaped in a two-step process, which is costly and can cause quality issues.

Due to thickness variations that occur in the curing process it is hard to get good precision in components that require molds on both sides.

When shaping Z-profiles, problems also occur because of bigger shear stresses between the laminates [14]. This can lead to difficulties in removing excess matrix and air in the material. This causes a delamination in the material, an example is illustrated in Figure 4.

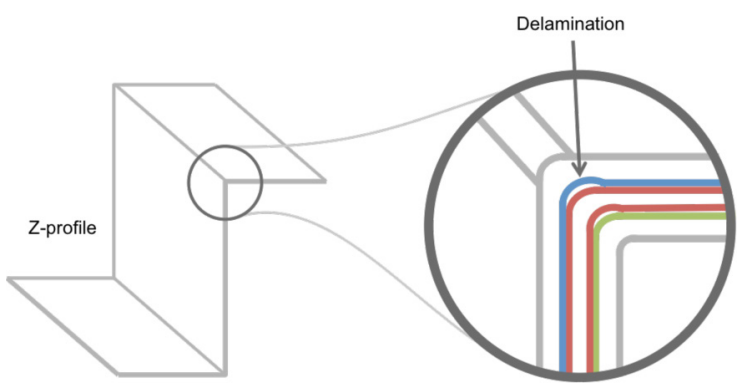

Figure 4. Example of a Z-profile and how delamination can appear in the radius.

Rule 2. Avoid components with Z-profiles.

\section{Assembly of Uncured Components of Pre-Impregnated Materials}

Before the pre-impregnated material is cured it is sticky, which makes it hard to positionally adjust in the assembly process. The material cannot be pushed along another part into the right position, as seen in Figure 5. To solve this material property problem, it is essential to design the components in a way that makes it possible to assemble the parts so they can be leveled against one surface at a time.

Many times, the assembly of uncured components can be adjusted by smart production planning where the components assemble against each other in steps. An example of this can be seen in Figure 6.

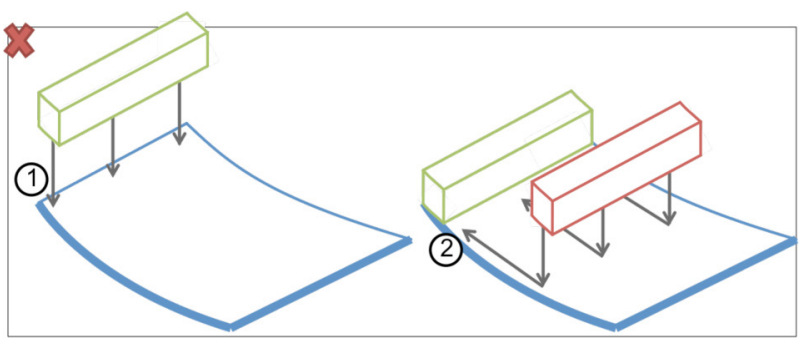

Figure 5. Example of difficult assembly of uncured components due to adhesion of materials.

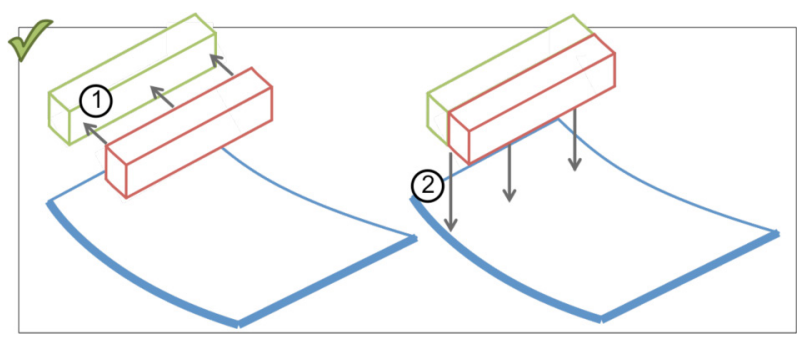

Figure 6. Example of how assembly of uncured components can be solved by assembly in smart steps.

Rule 3. Assemble uncured parts one surface at the time.

\section{Weight Optimization of Components}

One way to enable weight-optimized components is by minimizing the amount of material used. This can be done by e.g. cutting out so-called lightweight holes, where the requirements for strength in the component make it possible. This will require extra finishing work after the curing that should be avoided. Finishing work that implies extra processing steps can be avoided by optimizing the amount of laminate that is used [13]. By tapering off the amount of laminate in areas with lower requirements on strength, the components' weight is lowered the need for finishing work is negated [11]. An example of this can be seen in Figure 7.

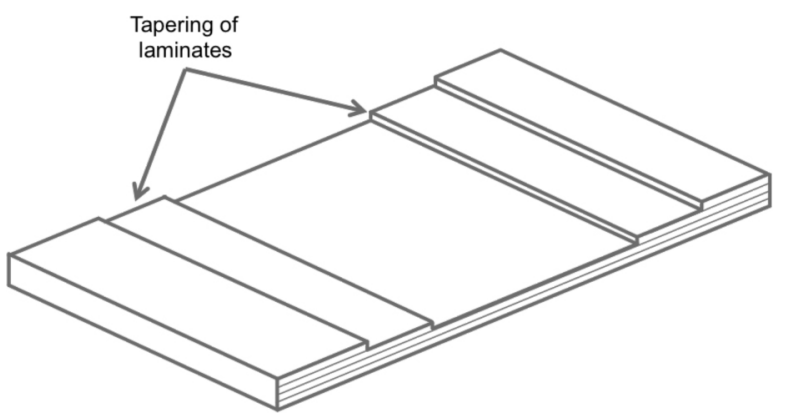

Figure 7. Example of weight optimization by tapering of laminates to reduce the thickness.

An added benefit of this method of weight optimization is the lowered amount of material needed, which should result in a lower cost.

Rule 4. Reduce weight by tapering laminates.

\section{Considerations When Setting Tolerances}

In the cases when designing CFRP components requires a high precision in geometry by small margins or fine surface finish, there is often a need for expensive molds or finishing work. If the design can 
be given higher tolerances, these extra procedures can sometimes be avoided and the manufacturing cost reduced. The designer should be advised that larger tolerances can lead to other problems when assembling, where the lack of precision can create other kinds of extra work, e.g. shimming.

Rule 5. Set tolerances with as big a margin as possible.

\section{Accessibility in Assembly}

To facilitate assembly and therefore reduce lead time and manufacturing costs access with e.g. assembly tools has to be considered in the design $[\underline{16}, \underline{21}]$. Many fasteners require access from both sides, which can be hard in small spaces. This concerns both access of tools and space for the geometry of the fastener. An example of obstructed access in assembly can be seen in Figure 8.

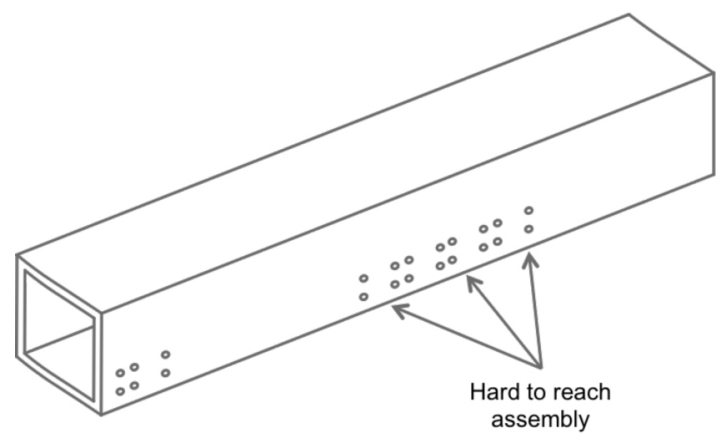

Figure 8. Example of design that obstruct assembly with fasteners.

To facilitate access for assembly in the worst cases, cut-outs in the component could be required. This implies extra finishing work that should be avoided to minimize costs and lead time. If possible, fasteners should be placed where assembly is easier to perform [21] .

Rule Make sure that there is enough accessibility for assembly 6. operations.

\section{Accessibility when Performing Non-Destructive Testing}

Just as when assembling, some extra space might be necessary when performing NDT. The testing is often performed with different sized tools that all need access to the areas concerned. Areas that in the first hand can lead to difficulties in NDT are interior radii, e.g. corners and edges [13]. In some cases, special tools must be developed to conduct the NDT in these areas.

If the NDT cannot be conducted in parts of the components, the strength of the structure cannot be assured. This might require that the construction be compensated for through reinforcements that also could imply extra weight and a higher cost.

Rule Make sure that there is enough accessibility for

7. nondestructive testing operations.

\section{Demolding Components from Mold}

Because CFRP components are cured in an elevated temperature, changes in the form of expansions and contractions of the material, and curing of the matrix, will lead to the component getting stuck to the mold. To enable demolding (i.e. removing) the component from the mold, it is important to have thought about at least on direction to demold with a positive angle of release. An example of what demolding can look like and angles of release that are required can be seen in Figure 9 and Figure 10.

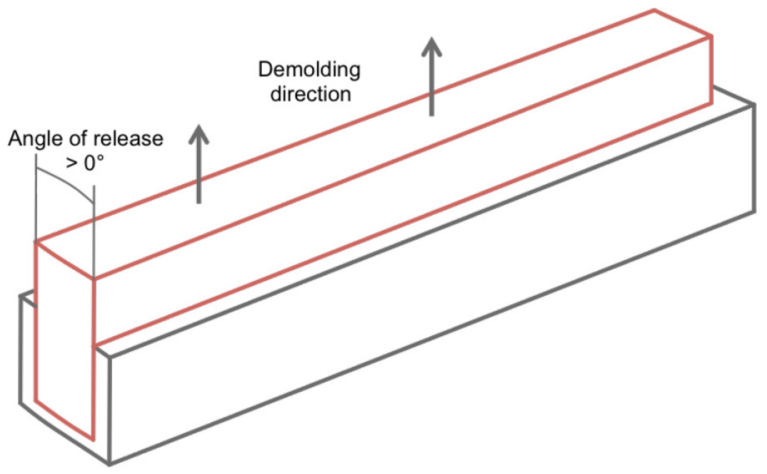

Figure 9. Example of demolding of component from mold where positive angle of release is required in one direction.

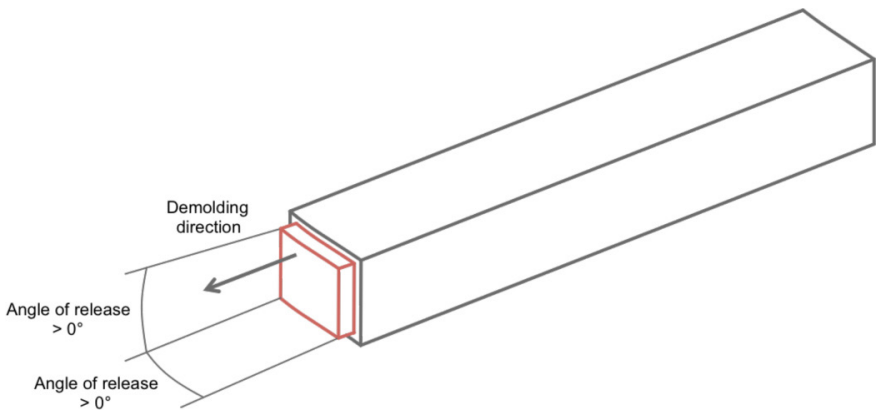

Figure 10. Example of demolding from mold where positive angle of release is required in several directions.

The deeper the construction, the wider the angle of release must be; one rule of thumb is $0.5^{\circ}$ for shallow designs (less than $15 \mathrm{~cm}$ ), while deeper designs can require $1-3^{\circ}$ (more than $15 \mathrm{~cm}$ ) [15]. Another aspect that can affect the size of the angle is the surface finish of the component and the mold, where a rougher finish requires a wider angle [15].

Rule Make sure there is a clear demolding direction with enough 8. positive angle of release.

\section{Components with Enclosed Molds}

Another difficulty that can occur is when the components' mold is enclosed within the design, as seen in Figure 11. If a clear demolding direction is missing then the mold must be demolded in some other way, e.g. by using a mold that can be disassembled inside the component. This will lead to a more complex demolding procedure, which in turn leads to longer lead times and higher component manufacturing costs.

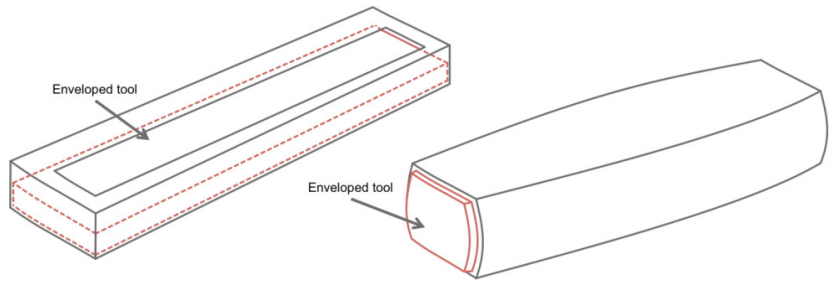

Figure 11. Examples of component designs where the mold in enclosed. 
There is also a kind of mold, called an "offer mold" that is cured into the component and becomes a part of the structure. This will lead to individual molds for each component, but also gives the component an extra cost.

Rule 9. Avoid component designs that enclose the mold.

\section{Placement of the Mold}

Due to the carbon fiber and matrix variations that exist in CFRP there is always a thickness variation that occurs in cured components, and this variation leads to uneven surfaces [13]. The thickness variations only occur in the opposite direction of the side to where the mold is placed. The side where the mold is placed will have good geometrical precision and surface finish, as illustrated in Figure 12.

Bag side

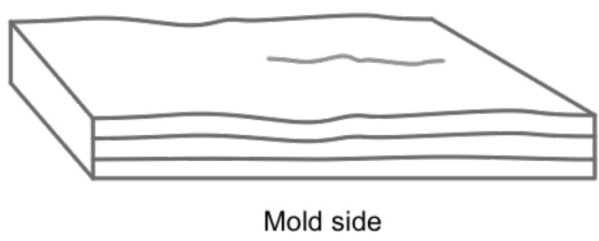

Figure 12. Simplified example of how thickness variations can look in a CFRP component.

The choice of where to place the mold is therefore essential, since the surface finish can affect e.g. assembly, NDT and aerodynamics. Generally, the mold should be placed against the surfaces that will create the aerodynamic shape to avoid finishing work on these. In cases where this is not relevant or where an aero-dynamical surface is missing, the guidelines described below should be used.

\section{a. Surface to Assemble Cured Components}

If the component must be assembled against something or has something assembled onto it, the tolerance demands are higher. This means that assembly should be done on the side of the mold. If assembly has to be done against the surface that was not against the mold, some finishing work will likely need to be done in the form of liquid shims between the components. These liquid shims consist of epoxy, and their use entails a time-consuming and hazardous work process that should be avoided. Epoxy also has to cure, which creates extra lead time and causes health risks such as allergies.

Rule Assemble components onto the side of the CFRP component 10. that has been facing the mold.

\section{b. Surface for Non-Destructive Testing}

To perform successful NDT with a clear picture of the material's structure, an even surface is required to conduct the test against. As with assembly, it is therefore preferable to conduct the test against the surface that has been cured against the mold.

Rule Perform non-destructive testing on the side that has been

11. facing the mold.

\section{Summation of the Rules}

The guidelines from the empirical and theoretical studies were condensed into the following list of rules:

Rule 1. Avoid double-bent surfaces as much as possible.

Rule 2. Avoid components with Z-profiles.

Rule 3. Assemble uncured parts one surface at the time.

Rule 4. Reduce weight by tapering laminates.

Rule 5. Set tolerances with as big a margin as possible.

Rule 6. Make sure that there is enough accessibility for assembly operations.

Rule 7. Make sure that there is enough accessibility for nondestructive testing operations.

Rule 8. Make sure that there is a clear demolding direction with enough positive angle of release.

Rule 9. Avoid geometry that will enclose the mold.

Rule 10. Assemble components onto the side of the CFRP component that has been facing the mold.

Rule 11. Perform non-destructive testing on the side that has been facing the mold.

Based on the product's design, the rules can either be applied to the entire CFRP component or specific parts of it. For complex integrated designs, it can be of value to look at both individual parts as well as the entire component to get a holistic overview.

As mentioned earlier in cases where the rules are not possible to apply, they can still help indicating potential problems. The problems then instead could be prevented by e.g. extra controls or more careful manufacturing instructions.

\section{Discussion}

These guidelines and rules have been developed as a part of a wider DFM/A strategy at Saab Aerostructures. They are meant to be worked with as a part of a structured work process with other traditional DFM/A tools to complement the above-stated rules and guidelines. This paper only presents a part of the process (concerning CRFP component manufacturing), but it is an essential part in an overall DFM/A suggested strategy. A structured development process could be beneficial in many ways [10]. These guidelines and rules should help to create an explicit decision process by reducing the risk of making unsupported decisions. By following the overall work process, important activities are not forgotten, and by applying suggested tools, the process becomes largely self-documented.

The purpose of the guidelines is to educate and make the designer aware of the consequences a design choice could have on manufacturability. The designer also needs to be aware that some of these rules may be contradictious, and in these cases must argue for and choose the best option on other terms. Trade-offs are one of the biggest challenges in product development, and need to be carefully considered [10]. The guidelines and rules need to be used in a wider context with e.g. final product assembly aspects in mind as well. The production process is much larger than only the manufacturing of the individual component itself, and it is therefore essential that the entire manufacturing process is considered to avoid suboptimization.

$\mathrm{DFM} / \mathrm{A}$ is one way to import knowledge from the manufacturing process and raise the designers' understanding [21]. 
When the guidelines are not possible to apply, other potential actions can still be applied to ensure quality in the manufacturing process, e.g. extra controls or meticulous instructions on critical production steps. Manual inspection during the manufacturing process is still a core activity for the manufacturing of CFRP components to ensure the desired quality [1ㅡ].

Most of the rules come from earlier knowledge and the rules themselves are not where this paper is unique. Usability of the guidelines and rules has been crucial in the development. The amount of information has been kept down to an amount that has been assessed by the involved development groups and a reasonable amount of time needs to be invested to use it. The outcome has been said to be worth the time and effort of application. Some rules have been changed, reformulated, omitted or added in order to meet the expectations of the designers who have tested to work with them. The final list of rules has been confirmed to include the most relevant and important for the designers at SAAB Aerostructures.

As Ullman [16] states, good communication is a key factor for a successful product to avoid the "over the wall" problematic that might lower quality and lead to unnecessary costs. By applying these design guidelines in the concept design phase of the development process, it should reduce problems with "over the wall"; this is due to introducing an awareness of the upcoming manufacturing process in earlier steps than is currently is done. In this way, the designer and manufacturer can start to speak the same language and together find the best solutions and compromises that avoid expensive late changes in the design.

Since changes late in the process can be very costly or even impossible, it is essential to prevent this as much as possible [18]. Even though the concept and detailed design phases might be extended in this work process, cost should be recovered in the manufacturing process and unnecessary costs reduced later on, e.g. by lowering the scrap rate and raising the quality [21]

CFRP materials are increasing in popularity, and wealth of knowledge exists both in academia and industry, primarily about the materials' properties. Despite this, there are not currently DFM/A guidelines or rules with this amount of detail published for CFRP, and especially not for pre-impregnated materials. Pre-impregnated CFRP differs in many ways from other ways to manufacture CFRP components, and therefore has other aspects to consider in production [15]. Delamination and double-curvature, for example, are explicit issues when working with pre-impregnated laminates, and issues such as angle of release are applicable to other CFRP forms as well.

Since the guidelines were developed and derived in close collaboration with SAAB Aerostructures and its current manufacturing technology, it might be necessary to address other issues in other manufacturing processes at other companies. These guidelines and rules will also have to be further developed at the same pace as new manufacturing processes develop and change.

\section{Conclusions}

Based on an empirical and theoretical study, 11 design guidelines and $11 \mathrm{DFM} / \mathrm{A}$ rules on designing carbon fiber-reinforced plastic components were derived. These guidelines and rules, if used in a wider context, should contribute to a design that reduces lead-time and provides higher quality manufactured components as well as final products. The quality of the manufactured components should rise since unnecessary manufacturing issues can be anticipated and prevented with these rules and guidelines. One of the most important results from this paper is not the knowledge behind the rules or guidelines but rather that it is possible to concentrate an extensive amount of important information and several aspects into approachable and usable information. This summarized list of rules and the guidelines to support the rules can actually be used in day-today work. This aspect seems to be lacking in other research today.

The guidelines and rules have not been applied outside SAAB Aerostructure, but could in theory provide support and help for other companies with similar manufacturing processes in the aerospace industry, or even in other types of businesses. The guidelines are today also adapted for the CFRP materials used at SAAB Aerostructure. This could be of interest to investigate in future research how generalizable the rules and guidelines are, both in other businesses as well as how the rules differ and what similarities exist between different material properties. If these guidelines and rules are implemented in a development process, they should also be accompanied by continuous future work to keep them current and up-to-date.

\section{References}

1. Marketline, "Airlines in the United", 2014, Airlines Industry Profile: United States. p. 1-37.

2. Tang, C.S., J.D. Z., and Nelson J.I., "Managing new product development and supply chain risks : The Boeing 767 case". Supply Chain Forum: An International Journal, 2009. 10(2): p. 74-86.

3. SAAB Group. 2014. "Aerostructures aircraft design and manufacturing" [Online]. http://saab.com/commercialaeronautics/aerostructures/: SAAB Group. [Accessed 20 June 2015]

4. US Department of Defens, "Composite Materials Handbook. Volume 3. Polymer Matrix Composites Materials Usage, Design and Analysis, MIL-HDBK-17". 2002.

5. Andersson, F., Hagqvist A., Sundin E., and Björkman M., "Design for Manufacturing of Composite Structures for Commercial Aircraft: The Development of a DFM strategy at SAAB Aerostructures". Procedia CIRP, 2014: p. 362.

6. Jensen, J. and Nilsson S., "DFM/A method for integrated structures of carbon fiber reinforced plastic : Further development of methodology for SAAB Aerostructures (SWEDISH)", 2016, Linköping University: Linköping.

7. Bell, J. and Nilsson B., "Introduktion till forskningsmetodik". 2006: Lund : Studentlitteratur, 2006.

8. Holme, I.M., Solvang B.K., and Nilsson B., "Forskningsmetodik : om kvalitativa och kvantitativa metoder". 1997: Lund : Studentlitteratur, 1997.

9. Huang, G.Q. and Mak K.L., "The DFX shell: A generic framework for developing design for X tools". Robotics and Computer-Integrated Manufacturing, 1997. 13(3): p. 271-280.

10. Ulrich, K. and Eppinger S., "Product Design and Development". 5th edition ed. 2011: McGraw-Hill/Irwin. 
11. Damberg, H., "Komposithandboken : polymerbaserade fiberkompositer". 2001: Stockholm : Sveriges verkstadsindustrier (VI) : Industrilitteratur, 2001

12. Kaw, A.K., "Mechanics of composite materials". 2 ed. Mechanical engineering series. 2006: Boca Raton : Taylor \& Francis.

13. Baker, A., Dutton S., and Kelly D., "Composite materials for aircraft structures". AIAA education series. Vol. 2. ed. 2004: Reston : American Institute of Aeronautics and Astronautics, cop. 2004.

14. Long, A.C., "Composites forming technologies". 2007: Cambridge : Woodhead, 2007.

15. Bralla, J.G., "Design for manufacturability handbook". McGraw-Hill handbooks. Vol. 2. ed. 1999: New York : McGraw-Hill, cop. 1999.

16. Ullman, D., G., "The Mechanical Design Process". 2002, New York: McGraw-Hill Higher Education.

17. Lindahl, M., "Engineering Designers' Requirements on Design for Environment Methods and Tools", 2005, The Royal Institute of Technology: Stockholm.

18. Lindahl, M. and Sundin E., "Product Design Considerations for Improved Integrated Product/Service Offerings", in Handbook of Sustainable Engineering. 2012, Springer.

19. Mascitelli, R., "The lean product development guidebook : everything your design team needs to improve efficiency and slash time-to-market". 2007: Northridge, Calif. : Technology Perspectives, 2007.

20. Gay, D. and Hoa S.V., "Composite materials : design and applications". Vol. 2. ed. 2007: Boca Raton, Fla. : CRC Press, cop. 2007.

21. Boothroyd, G. and Alting L., "Design for Assembly and Disassembly". CIRP Annals - Manufacturing Technology, 1992. 41(2): p. 625-636.

\section{Contact Information}

Corresponding author:

Name: Sara Nilsson

Tel.: +46-13281184

Sara.K.Nilsson@liu.se

\section{Acknowledgments}

The authors would like to thank the Swedish Governmental Agency for Innovation Systems (VINNOVA) for financing this research project, "Next Generation Composites Structures for Commercial Aircraft", through its Grön flygteknisk demonstration" program. The authors would also like to thank everyone involved from SAAB Aerostructures who supported them during the empirical studies.

\section{Abbreviations}

ATL - Automated Tape Laying

CFRP - Carbon Fiber-Reinforced Plastic

DFM/A - Design for Manufacturing and Assembly

NDT - Non-Destructive Testing

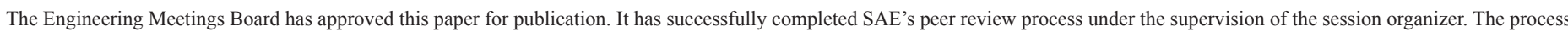
requires a minimum of three (3) reviews by industry experts.

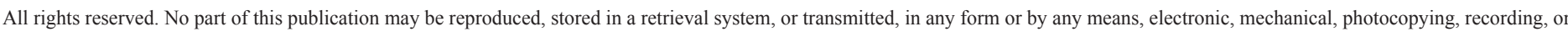
otherwise, without the prior written permission of SAE International.

Positions and opinions advanced in this paper are those of the author(s) and not necessarily those of SAE International. The author is solely responsible for the content of the paper.

ISSN 0148-7191

http://papers.sae.org/2016-01-2124 